\title{
FILTRO GRAVITACIONAL DE CARVÃO ATIVADO IMPREGNADO COM COMPOSTOS DE COBRE E PRATA PARA MELHORIA DA QUALIDADE DA ÁGUA.
}

\author{
N. U. YAMAGUCHI ${ }^{1,2}$, S. A. L. ABE ${ }^{1}$, J. M. FRANCO ${ }^{1,2}$, F. S. ARAKAWA ${ }^{1}$, O. A. A. SANTOS ${ }^{1}$, \\ A. M. S. VIEIRA ${ }^{3}$, R. BERGAMASCO ${ }^{1}$ \\ ${ }^{1}$ Universidade Estadual de Maringá, Departamento de Engenharia Química \\ ${ }^{2}$ Centro Universitário UniCesumar, Departamento de Engenharia \\ ${ }^{3}$ Universidade Estadual de Maringá, Departamento de Engenharia de Alimentos \\ E-mail para contato: nataliaueda@hotmail.com
}

\begin{abstract}
RESUMO - A presente pesquisa desenvolveu um filtro utilizando carvão ativado granular em um sistema gravitacional simples e econômico para a melhoria da qualidade da água tratada destinada ao consumo humano. Foram impregnados compostos metálicos na superfície carvão ativado com $0,5 \%$ de prata e $0,5 \%$ de cobre para obter atividade bactericida. Foram utilizadas técnicas instrumentais tais como microscopia eletrônica de varredura, espectrometria de energia dispersiva difração de raios-x, mapeamento elementar e microscopia eletrônica de transmissão para caracterizar o adsorvente após a impregnação de metais. A eficiência do filtro foi verificada através da avaliação de remoção de cloro livre e de remoção de Escherichia coli. O filtro apresentou remoções de cloro e E. coli superiores a 94 e $99 \%$, respectivamente. Portanto, o filtro doméstico de carvão ativado impregnado com compostos metálicos de cobre e prata, revelou ter alto potencial na melhoria da qualidade da água tratada.
\end{abstract}

\section{INTRODUÇÃO}

A qualidade da água destinada ao consumo humano, mesmo quando há um tratamento convencional centralizado, pode muitas vezes ser duvidosa. Isso pode ocorrer em seu caminho até o destino final, devido à avarias nas tubulações, quedas de pressão, manutenção deficiente das unidades de tratamento de água e assepsia precária das caixas d'água (Brick et al., 2004; Rebouças, 2004).

Dentre os principais fatores de risco da água para consumo, principalmente em países em desenvolvimento, destacam-se os riscos associados à contaminação microbiológica (PeterVarbanets et al., 2009). A água pode disseminar doenças, atuando como um portador passivo de patógenos infecciosos, principalmente relacionados à contaminação fecal das fontes de água (Gadgil, 1998). 


\section{9 a 22 de outubro de 2014 \\ Florianópolis/SC}

Com a finalidade de garantir que a água de consumo chegue ao consumidor final com qualidade assegurada nos casos onde o tratamento centralizado não é eficiente, sistemas de tratamento de água descentralizados/domésticos simples têm sido utilizados para atuarem como uma barreira final para o consumidor (Peter-Varbanets et al., 2009).

O carvão ativado tem sido largamente utilizado no tratamento de água devido ao seu alto poder de adsorção, para controle de cor e odor, bem como para a remoção de compostos orgânicos, metais tóxicos e cloro (Hetrick et al., 2000). Porém, apesar de sua área superficial elevada, o carvão ativado tem baixa eficiência na remoção de microrganismos. A incorporação de metais na sua superfície tem sido utilizada por diversos autores (Miotto et al., 2000; Park e Jang, 2003; Zhao et al., 2012) para aumentar a eficiência bacteriológica para produção de filtros domésticos que garantam a qualidade da água potável para o consumidor final.

Assim, este trabalho utilizou-se de um sistema de filtração gravitacional composto de carvão ativado impregnado com metais para a melhoria da qualidade da água destinada ao consumo humano.

\section{MATERIAIS E MÉTODOS}

Foi realizada a avaliação do filtro com carvão ativado impregnado com compostos metálicos de cobre e prata e do filtro com carvão ativado sem a impregnação de metais, a fim de comparar as eficiências em relação à remoção bacteriológica e à remoção de cloro. Além da avaliação da eficiência do filtro, o carvão ativado impregnado foi caracterizado através de técnicas instrumentais tais como microscopia eletrônica de varredura, espectrometria de energia dispersiva, mapeamento elementar e microscopia eletrônica de transmissão.

\subsection{Impregnação de Compostos Metálicos no Carvão Ativado}

Utilizou-se carvão ativado obtido da casca de coco de dendê granular de 16X40 mesh (Bahiacarbon Agroindustrial Ltda). Para melhorar o desempenho bactericida do carvão ativado foram impregnados metais em sua superfície. Utilizou-se a técnica da impregnação úmida, com excesso de solvente, com concentração em massa de $0,5 \%$ de cobre e $0,5 \%$ de prata. A escolha do método e das concentrações de metais foi baseada em trabalhos anteriores (Yamaguchi, 2013; Silva-Medeiros, 2012, Miotto et al.,2000; Arakawa, 2011).

A impregnação de metais foi realizada conforme descrito por Silva-Medeiros (2012) e Yamaguchi (3013) em evaporador rotativo. Adicionou-se carvão ativado granular (CAG) e água deionizada na proporção $1: 1(\mathrm{~m} / \mathrm{m})$ em balão de evaporador rotativo, e em seguida, sulfato de cobre e nitrato de prata em solução $(30 \mathrm{ml})$ em quantidades suficientes para atingir a concentração desejada. Essa mistura permaneceu então sob agitação (20 rpm) e aquecimento $\left(60^{\circ} \mathrm{C}\right)$ por 24 horas. Depois desta etapa, o excesso de água foi evaporado com pressão negativa à $80^{\circ} \mathrm{C}$ e a amostra foi levada para secagem em estufa à $100^{\circ} \mathrm{C}$ por 24 horas. Após a secagem, $\mathrm{o}$ carvão foi submetido ao tratamento térmico em forno mufla à uma temperatura de $350^{\circ} \mathrm{C}$ por 5 
horas. Na última etapa da impregnação a amostra foi submetida a uma lavagem a fim de remover os metais que não foram impregnados, seguida de secagem em estufa a $100^{\circ} \mathrm{C}$.

\subsection{Caracterização do Meio Filtrante}

O carvão ativado foi caracterizado através das técnicas de microscopia eletrônica de varredura, espectrometria de energia dispersiva e microscopia eletrônica de transmissão. As morfologias superficiais do carvão ativado foram verificadas através de microscopia eletrônica de varredura (MEV) em microscópio Shimadzu SS-550 - Scanning Electron Microscope. No mesmo equipamento foram feitas também as análises de espectrometria de energia dispersiva (EDX) para determinar a composição das superfícies dos carvões ativados e o mapeamento elementar. A micrografias de microscopia eletrônica de transmissão (MET) foram feitas em microscópio JEOL modelo JEM-1400 Electron Microscope. Os equipamentos pertencem ao Complexo de Centrais de Apoio à Pesquisa (COMCAP) da Universidade Estadual de Maringá (UEM).

\subsection{Avaliação do Meio Filtrante}

Sistema Gravitacional de Filtração: O módulo de filtração gravitacional utilizado neste trabalho para avaliar os filtros produzidos encontra-se ilustrado na Figura 1.

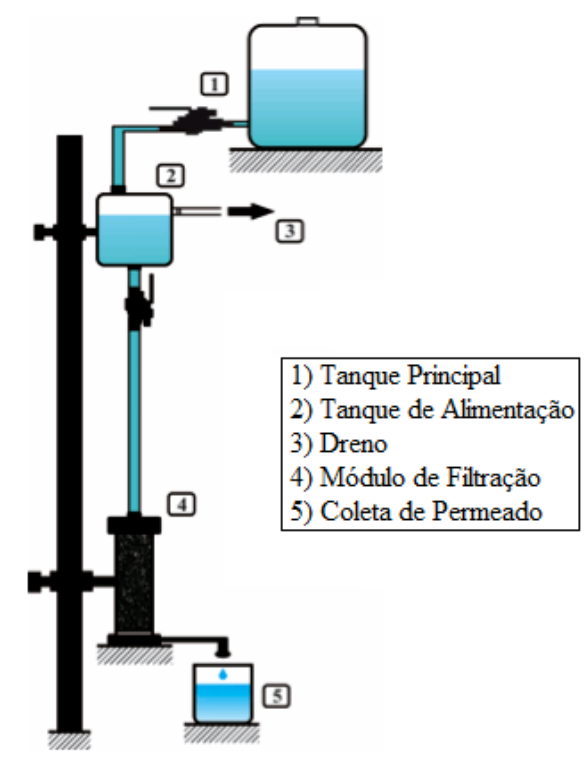

Figura 1 - Esquema do sistema de filtração gravitacional.

O sistema era composto por um tanque principal com capacidade de $20 \mathrm{~L}$ (1), que armazenava a água a ser tratada e supria o tanque de alimentação (2). O dreno (3) mantinha o nível de água constante no tanque de alimentação, com a finalidade de não alterar a altura da coluna d'água (3,1 metros), e conseqüentemente mantendo a pressão constante $(0,31$ bar, resultante da coluna d'água) e finalmente a água filtrada era coletada após a filtração (5). 
Avaliação de remoção de cloro livre: A avaliação de remoção de cloro foram realizadas durante a filtração de água da torneira até o final da vida útil do filtro $(600 \mathrm{~L})$. Foram realizadas análises de acordo com o Standard Methods for the Examination of Water and Wastewater (APHA, 2012).

Avaliação de Remoção Microbiológica: Para a avaliação de remoção de Escherichia coli, utilizou-se água contaminada artificialmente com concentração entre $10^{5}$ e $10^{6}$ UFC/100 ml, e realizada de acordo com o descrito pela NBR 16098 (ABNT, 2012). Depois da filtração da água contaminada, a remoção de $E$. coli foi avaliada utilizando-se a técnica da membrana filtrante, conforme descrito no Standard Methods for the Examination for Water and Wastewater (APHA, 2012). Estes ensaios foram realizados no início e no final da vida útil do filtro, isto é, antes e após a passagem de 600 litros de água de torneira no filtro.

\section{RESULTADOS E DISCUSSÃO}

\subsection{Caracterização do Meio Filtrante}

As micrografias realizadas no microscópio eletrônico de varredura e seu mapeamento elementar juntamente com o espectro de energia dispersiva encontram-se na Figura 2.

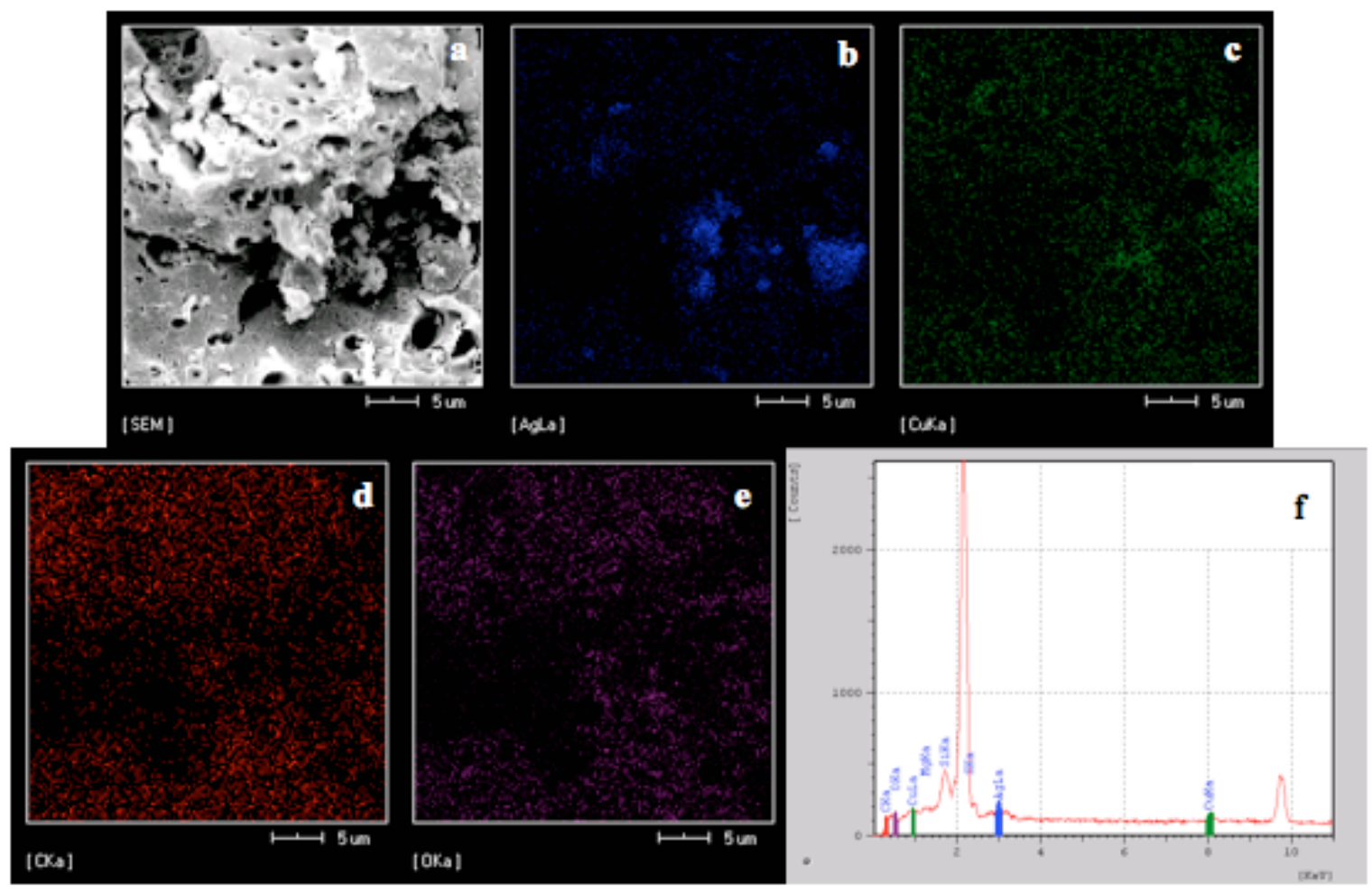

Figura 2 - Micrografia eletrônica de varredura $\left(\mathrm{MEV}^{r}\right)$ para a amostra de carvão ativado impregnado com compostos metálicos de cobre e prata (a), mapeamento elementar para a prata (b), cobre (c), carbono (d) e oxigênio (e) e espectro de energia dispersiva (EDX) (f). 
Pode-se observar a presença de carbono, oxigênio, magnésio, sílica, enxofre, cobre e prata no espectro de energia dispersiva (Figura 2f). O Pico de carbono já era esperado, tendo em vista que o carvão ativado é de origem vegetal (orgânico). Segundo Bansal (2005) a composição elementar do carvão ativado típico é de $88 \% \mathrm{C}, 0,5 \% \mathrm{H}, 0,5 \% \mathrm{~N}, 1 \% \mathrm{~S}$ e 6 a $7 \%$ de $\mathrm{O}$, variando de acordo com o tipo de matéria-prima e as condições do processo de ativação. Justificando desta forma também, a presença do enxofre. A baixa concentração de nitrogênio e hidrogênio explica o fato de não terem sido detectados. Além disso, o hidrogênio devido ao seu baixo peso molecular não é detectável por este método. Todos elementos, com exceção do cobre e prata, são comuns em carvões ativados produzidos de material vegetal, como é o caso do carvão ativado utilizado neste trabalho que é originado de casca de coco de dendê (Haro et al., 2012; Giri et al., 2012).

O mapeamento elementar foi realizado para os picos de carbono, oxigênio, cobre e prata. Para o elemento carbono, nota-se uma distribuição uniforme, assim como o oxigênio, porem em maior quantidade. Quando compara-se os compostos metálicos que foram impregnados, nota-se que a prata foi distribuída de forma desuniforme formando aglomerados enquanto que o cobre foi distribuído de forma uniforme por toda a amostra. Srinivasan et al. (2013) encontraram micrografias de mapeamento elementar semelhantes aos obtidos neste trabalho para o carbono e prata.

A análise de microscopia eletrônica de transmissão foi realizada com o objetivo de avaliar melhor a impregnação de metais no carvão ativado. Suas micrografias encontram-se na Figura 3.
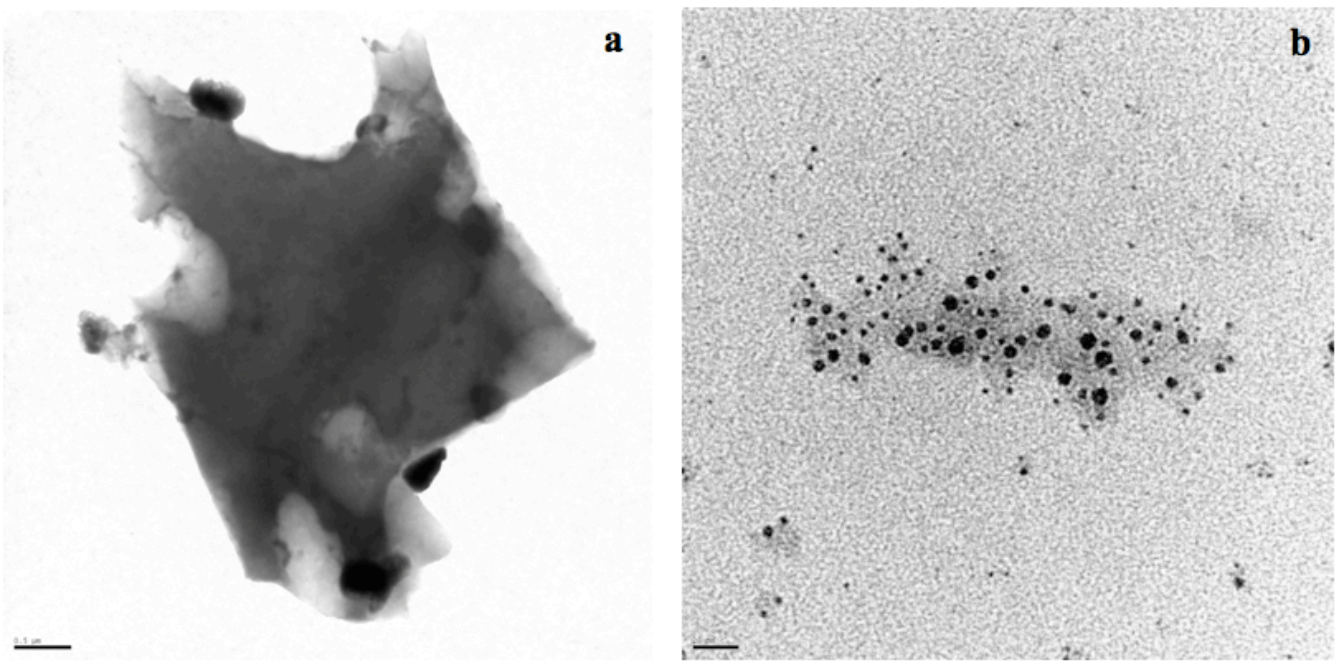

Figura 3 - Micrografia eletrônica de transmissão na escala micro (a) e na escala nano (b).

Na Figura 3a podemos observar claramente aglomerados escuros de formato esférico com tamanhos na faixa de $0,5 \mu \mathrm{m}$, estes aglomerados são devido à impregnação de metais ou óxidos metálicos. A parte mais clara é característica do carvão ativado por ser um material poroso e amorfo. Diversos autores utilizam da mesma técnica para visualizar a presença de metais e óxidos metálicos na superfície do carvão ativado (Srinivasan et al., 2013; Fierro et al., 2009). 
Pode-se observar na Figura $3 \mathrm{~b}$ estruturas esféricas na faixa de 5 a $10 \mathrm{~nm}$, indicando a presença de nanopartículas. Portanto, os metais foram encontrados no carvão ativado com diferentes estruturas, como nanopartículas ou como aglomerados.

\subsection{Avaliação do Meio Filtrante}

Os resultados obtidos para a eficiência de remoção de cloro e remoção de $E$. coli encontram-se apresentados na Tabela 4.

Tabela 4 - Parâmetros avaliados para o filtro de carvão ativado

\begin{tabular}{cccc}
\hline \multirow{2}{*}{ Filtro } & \multicolumn{3}{c}{ Remoção (\%) } \\
\cline { 2 - 4 } & Cloro livre & E. coli inicial & E. coli final \\
\hline CAG & 94 & 85,22 & 60,61 \\
CAG/Ag/Cu & 95 & 99,96 & 99,87 \\
\hline
\end{tabular}

Os filtros de carvão ativado apresentaram remoções de cloro superiores a 94\% para ambos os filtros, comprovando o alto poder de adsorção de cloro pelo carvão ativado. A classificação dos filtros produzidos segundo a NBR 16098 (ABNT, 2012) é de classe I, com remoções superiores a $75 \%$.

Já em relação à eficiência bacteriológica observou-se um grande aumento para o filtro com carvão ativado impregnado com metais. O efeito bactericida de metais já eram resultados esperados devido ao conhecido efeito oligodinâmico, que é caracterizado pelos efeitos letais que íons metálicos exercem sobre micro-organismos, mesmo em pequenas quantidades (Pelczar et al., 2005).

O resultado para o filtro impregnado com compostos metálicos de cobre e prata potencializou o efeito oligodinâmico, apresentando um efeito de desinfecção sinérgico, conhecido pela ação de íons prata e cobre sobre micro-organismos, onde íons cobre se ligam à parede da célula permitindo a entrada de íons prata (Yahya e Gerba, 1992). Este efeito resultou em remoções superiores a 99\%, conforme exigido pela NBR 16098 (ABNT, 2012) mesmo em baixas concentrações de metais, enquanto que filtro sem a impregnação de compostos metálicos apresentou remoções bem inferiores. Arakawa (2011) utilizou impregnações de cobre e prata isoladamente, isto é, sem combinar os dois metais na mesma amostra, em concentrações de 5\% e obteve remoções de $99 \%$. O presente trabalho utilizou apenas um décimo desta quantidade de metais, diminuindo significativamente o custo do filtro através da combinação destes dois metais.

\section{CONCLUSÕES}

A impregnação de compostos metálicos de prata e cobre no carvão ativado foi comprovado pelo EDX. Através das análises de mapeamento e TEM pudemos observar que os metais se apresentaram na forma de aglomerados de aproximadamente $0,5 \mu \mathrm{m}$ e também na forma de nanopartículas na faixa de 5 a $10 \mathrm{~nm}$. 
O filtro com carvão ativado impregnado com compostos metálicos apresentaram resultados de acordo com a portaria 2.914 (Brasil, 2011) e com a NBR 16098 (ABNT, 2012), revelando ser uma ótima alternativa nas tecnologias de purificação e melhoria da qualidade da água destinada ao consumo humano utilizando a gravidade como força motriz. Pode-se então propor estas promissoras tecnologias para produção de filtros descentralizados para fins domésticos com o objetivo de melhoria da qualidade da água.

\section{AGRADECIMENTOS}

Os autores agradecem à Universidade Estadual de Maringá (UEM), ao Departamento de Engenharia Química (DEQ/UEM), ao Complexo de Centrais de Apoio à Pesquisa da Universidade Estadual de Maringá (COMCAP), ao apoio financeiro do Conselho Nacional de Desenvolvimento Científico e Tecnológico $(\mathrm{CNPq})$ e à empresa Purific do Brasil Ltda.

\section{REFERÊNCIAS}

ARAKAWA, F. S. (2011). Módulos de filtração gravitacional com carvão ativado impregnado com íons metálicos para obtenção de água destinada ao consumo humano. UEM, Maringá-PR. (dissertação de mestrado).

ABNT - ASSOCIAÇÃO BRASILEIRA DE NORMAS TÉCNICAS. (2012). NBR 16098. Aparelho para melhoria da qualidade da água para uso doméstico. ABNT, 1 ed.

APHA - AMERICAN PUBLIC HEALTH ASSOCIATION; AWWA - THE AMERICAN WATER WORKS ASSOCI-ATION; WEF - THE WATER ENVIRONMENT FEDERATION. (2012). Standard methods for the exami-nation of water and wastewater, ed. 22.

BANSAL, R. C.; GOYAL, M. Activated Carbon Adsorption. Primeira ed. CRC Press, 2005.

BRASIL. Ministério da Saúde. Portaria n 2.914, de 12 de dezembro de 2011. Diário Oficial da República Federativa do Brasil.

BRICK, T.; PRIMROSE, B.; CHANDRASEKHAR, R.; ROY, S.; MULIYIL, J.; KANG, G. (2004). Water contamination in urban south India: household storage practices and their implications for water safety and enteric infections. International Journal of Hygiene and Environmental Health. v.207, $473-480$.

FIERRO, V.; MUÑIZ, G.; GONZALEZ-SÁNCHEZ, G.; BALLINAS, M. L.; CELZARD, A. Arsenic removal by iron-doped activated carbons prepared by ferric chloride forced hydrolysis. Journal of Hazardous Materials, v.168, 430-437, 2009.

GADGIL, A. (1998). Drinking water in developing countries. Annual Review of Energy and the Environment, v.23, $253-286$.

GIRI, A. K.; PATEL, R.; MANDAL, S. Removal of $\mathrm{Cr}$ (VI) from aqueous solution by Eichhornia crassipes root biomass-derived activated carbon. Chemical Engineering Journal, v. 185- 186, p. 71-81, 2012. 
HARO, M.; RUIZ, B.; ANDRADE, M.; MESTRE, A.S.; PARRA, J.B.; CARVALHO, A.P.; ANIA, C.O. Dual role of copper on the reactivity of activated carbons from coal and lignocellulosic precursors. Microporous and Mesoporous Materials, v. 154, p. 68-73, 2012.

HETRICK, J.; PARKER, R.; PISIGAN, R.; THURMAN, N. (2000). "Progress report on estimating pesticide concentrations in drinking water and assessing water treatment effects on pesticides removal and transformation: a consulation". Briefing document for a presentation to the FIFRA Scientific advisory panel.

MIOTTO, D.M.M., MACHADO, N.R.C.F., LIMA S.M., PEREIRA, N.C., PRADO FILHO, B.D., ABREU FILHO, B.A., (2000). "Estudo da eficiência de filtros de carvão ativo impregnados com prata." Anais do XVII Simpósio Ibero-Americano de Catálise, Porto-Portugal, 16-21 Julho.

PARK, S. J.; JANG, Y. S. (2003). Preparation and characterization of activated carbon fibers supported with silver metal for antibacterial behavior. Journal of Colloid and Interface Science, v.261, 238-243.

PELCZAR, M; CHAN, E. C. S; KRIEG, N. R. Microbiologia: conceitos e aplicações v. 1. 2. ed. São Paulo: Makron Books, 2005.

PETER-VARBANETS, M.; ZURBRÜGG C.; SWARTZ, C.; PRONK, W. (2009). Decentralized systems for potable water and the potential of membrane technology. Water Research, v.43, 245 -265 .

REBOUÇAS, A. (2004). Uso inteligente da água. São Paulo: Câmara Brasileira do Livro, Escrituras Editora.

SILVA-MEDEIROS, F. V. (2012). Desenvolvimento de Materiais Filtrantes a Partir da Modificação de Meios Porosos para a Melhoria da Qualidade da Água Destinada ao Consumo Humano. UEM, Maringá-PR. (tese de doutorado).

SRINIVSAN, N. R.; SHANKAR, P. A.; BANDYOPADHYAYA, R. Plasma treated activated carbon impregnated with silver nanoparticles for improved antibacterial effect in water disinfection. Carbon, v. 7759, 2013.

YAMAGUCHI, N. U. (2013). Filtro híbrido de carvão ativado e membrana para purificação da água de consumo humano. UEM, Maringá-PR. (dissertação de mestrado).

YAHYA, M. T.; GERBA, C. P. Water disinfection systemand method. Chemical Abstract Service, v. 118:87342, 1992.

ZHAO, Y.; WANG, Z. Q.; ZHAO, X.; LI, W.; LIU, S. X. (2012). “Antibacterial action of silverdoped activated carbon prepared by vacuum impregnation.". Applied Surface Science, article in press. 